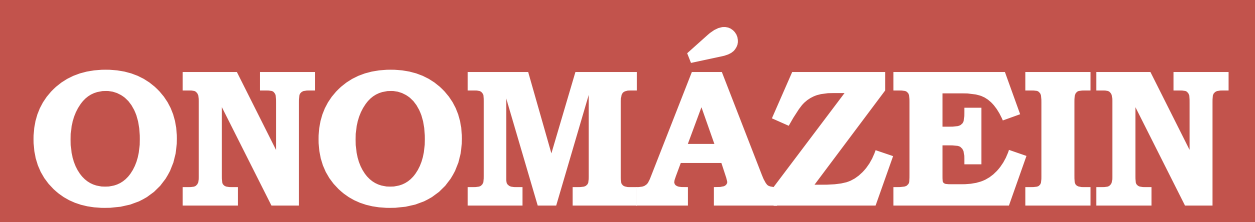

Revista de lingüística, filología y traducción
PONTIFICIA UNIVERSIDAD CATÓLICA DE CHILE FACULTAD DE LETRAS

\title{
Turismo de salud: análisis de páginas web y su traducción a otros idiomas
}

Health tourism: webpages and

translation analysis

\section{Ingrid Cobos López}

Universidad de Córdoba

Número especial

- VII -

Discurso turistico, lenguas y traducción

2020
ONOMÁZEIN | Número especial VII - Discurso turístico, lenguas y traducción: 41-62 DOI: 10.7764/onomazein.ne7.03 ISSN: 0718-5758

\section{(c) $(\mathbb{i})$}

Ingrid Cobos López: Departamento de Ciencias Sociales, Filosofía, Geografía, Traducción e Interpretación. Universidad de Córdoba. | E-mail:icobos@uco.es

Fecha de recepción: septiembre de 2019

Fecha de aceptación: febrero de 2020 


\section{Resumen}

En el mundo global en el que vivimos, la movilidad de personas de unos países a otros es cada vez mayor. Los motivos que favorecen dicho movimiento suelen ser vacacionales, laborales o porque se busquen unos servicios determinados en otros países debido a la calidad o el precio, entre otros. Uno de los servicios cada vez más demandado es todo lo relacionado con la salud; por ello, varios países han incrementado sus esfuerzos por tener una política sanitaria más internacional y tratar de posicionarse como destinos de salud. España reúne las mejores condiciones para convertirse en una potencia internacional del turismo de salud. Para ello, una de las primeras medidas que deben de cumplir los servicios sanitarios es su visibilidad en el mercado internacional, es decir, que sus páginas web y sus servicios estén disponibles a nivel global en otros idiomas. En el presente trabajo, pretendemos revisar las páginas web de los principales proveedores de servicios de salud en España y analizar las traducciones y los problemas que tuvieran, en su caso.

Palabras clave: turismo de salud; traducción de páginas web; problemas de traducción; visibilidad internacional.

\section{Abstract}

In the global world in which we live, the mobility of people from one country to another is increasing. The reasons that favor this movement are usually a holiday, labor or because certain services are better in other countries due to quality, price, etc., among others. One of the services that are increasingly sought are those related to health; therefore, several countries have increased their efforts to have a more international health policy and try to position themselves as health destinations. Spain meets the best conditions to become an international power of health tourism. For this, one of the first measures that health services must comply with is their visibility in the international market, that is, that their web pages and services are available globally in other languages. In the present work, we intend to review the web pages of the leading providers of health services in Spain and analyze the translations and the problems that they had, where appropriate.

Keywords: health tourism; webpage translation; translation problems; international visibility. 


\section{Introducción}

Si analizamos los datos ofrecidos por la Organización Mundial del Turismo (OMT), en 2018 viajaron por el mundo alrededor de 1.407 millones de personas ${ }^{1}$ con un crecimiento anual con respecto al anterior del 6 \%. Si nos centramos en las regiones, Europa recibe el 51 \% de dicho flujo internacional. Los motivos por los que se desplazan los turistas a esta zona son diversos. Según la OMT, el primer lugar lo ocupan el ocio y las vacaciones con un 59 \%; el segundo lugar, la salud, religión u otros motivos con el $27 \%$, y el tercer lugar, las razones laborales, con el 14\%.

En este sentido, podemos observar que la salud moviliza un porcentaje significativo del flujo internacional de personas. Según la OMT, el turismo de salud, sanitario o médico ha crecido exponencialmente en los últimos años y se ha convertido en una de las principales demandas en determinados destinos. Esto es debido al crecimiento global en el flujo de pacientes y profesionales de la salud, al desarrollo e innovación en tecnología médica y las posibilidades de financiación de los tratamientos, entre otros (Ministerio de Industria, Energía y Turismo, 2013).

La combinación de los conceptos de turismo y salud genera una serie de nociones como son "turismo médico", "turismo de salud" o "turismo de bienestar", que a menudo se usan indistintamente, pero que hacen referencia a conceptos diferentes. Estos conceptos han sido definidos a lo largo de los últimos años; sin embargo, sigue existiendo controversia en su delimitación. Así, autores como Smith y Puczko (2009) o Heung y otros (2010) entienden que el turismo de salud engloba al turismo médico y al de bienestar, mientras que otras instituciones e investigadores, como la OCDE o Connell (2006), observan que tienen algunas similitudes, pero plantean que son conceptos diferentes y lo justifican en sus definiciones. No obstante, la OMT o Sarwar y otros (2012) estiman que hay más similitudes que diferencias y consideran que se intercambian dichos conceptos con cierta frecuencia.

Por otra parte, cabe destacar que, aunque pudiera parecer una tendencia actual, el turismo de salud no es algo nuevo, sino que ya en la antigua Grecia y Roma existían los viajes a los baños termales o a los templos para realizarse curas o tratamientos, aunque estaban destinados principalmente para la élite social (Arias Aragones y otros, 2012). Asimismo, encontramos los viajes que hacían extranjeros de distintos países y condiciones sociales al hospital de Mansuri en busca de su sanación (Kazemy, 2007).

Es por ello por lo que la salud fue, ha sido y será uno de los servicios más demandados por los ciudadanos de todo el mundo. En este sentido, la unión de conceptos como el turismo y

1 Disponible en https://www.unwto.org/global-and-regional-tourism-performance [fecha de consulta: 1 de febrero de 2020]. 
la salud genera grandes oportunidades de negocio para aquellos países que lo deseen y que tengan visibilidad internacional (Ministerio de Industria, Energía y Turismo, 2013).

Por todo lo anterior, el objetivo principal del presente trabajo es analizar las páginas web de los facilitadores de turismo de salud españoles y comprobar si son accesibles para el cliente internacional, es decir, si se han traducido a otros idiomas para aumentar la visibilidad de sus servicios. Para alcanzar dicho objetivo principal, hemos planteado una serie de objetivos secundarios:

- Delimitar los conceptos de turismo de salud, turismo médico y turismo de bienestar.

- Establecer los orígenes de dicho fenómeno turístico.

- Revisar el panorama existente en España.

- Estudiar los facilitadores de turismo de salud en el país.

\section{Turismo de salud: definición y origen}

\subsection{Definición de los conceptos clave}

Consideramos necesario, en primer lugar, diferenciar entre el "turismo médico" y otros conceptos similares, como son el "turismo de salud" o el "turismo de bienestar". Según la OMT, existen tres conceptos clave relacionados con lo que en España se conoce como turismo de salud: Health Tourism, Medical Tourism y Wellness Tourism. En el informe emitido por la OMT a raíz del High Level Forum on Medical and Health Tourism, se define el Health Tourism² como "[f]orms of tourism which have as a primary motivation the contribution to physical, mental and spiritual health through medical and wellness-based activities which increase the capacity of individuals to satisfy their own needs and function better within their environment and society"; es decir, como una forma de turismo en la que el sujeto busca obtener una mejor salud física, mental y espiritual a través de ciertas actividades dentro del ámbito médico o de bienestar que ayuden a mejorar sus propias necesidades y a relacionarse en sociedad. Por otra parte, en el mismo informe, se define el Wellness Tourism (2019)3 de la siguiente manera:

A type of tourism activity which aims to improve and balance all of the main domains of human life including physical, mental, occupational, intellectual and spiritual. The primary motivation for the wellness tourist is to engage in preventive, proactive, lifestyle-enhancing activities such as fitness, healthy eating, relaxation, pampering and healing treatments;

2 Disponible en: https://webunwto.s3.eu-west-1.amazonaws.com/s3fs-public/2019-10/3_high_level_forum_on_medical_health_tourism_manuel_butler_unwto_o.pdf [fecha de consulta: 15 de enero de 2020].

lbíd. 
es decir, como una actividad turística mediante la cual se pretende mejorar y equilibrar cualquier ámbito de la vida humana, ya sea físico, mental, ocupacional, intelectual o espiritual. Su principal objetivo es el del compromiso con un estilo de vida preventivo y proactivo en el que se lleven a cabo actividades tales como fitness, una alimentación saludable, relajación o tratamientos de belleza o curativos. Observamos que existe una diferencia fundamental entre ambos conceptos. El primero es más amplio e incluye tanto el ámbito médico como el del bienestar general; además, este concepto incorpora el de medical tourism. El segundo se centra en aspectos relacionados con el bienestar general del ser humano. En este sentido, la OMT diferencia entre health tourism y medical tourism frente al Wellness tourism.

Por su parte, la Organización para la Cooperación y el Desarrollo Económicos (OCDE) se centra principalmente en dos conceptos y, a diferencia de la anterior, distingue entre medical tourism y health tourism. Dicha organización define el medical tourism "as when consumers elect to travel across international borders with the intention of receiving some form of medical treatment" (OECD, 2010: 30-31)4 centrando dicho concepto en torno a los servicios médicos. No obstante, aclara que por servicios médicos se refiere también a servicios dentales, cirugía estética, tratamientos de fertilidad, etc. Para la OCDE, este concepto forma parte de una noción más amplia, que es la de health tourism5.

Partiendo de las definiciones de la OCDE y de la OMT, distintos autores han delimitado los tres conceptos anteriormente mencionados, aunque la mayoría coincide en que el "turismo de salud" incluye las otras modalidades de turismo; así, por ejemplo, Smith y Puczko (2009) consideran que el turismo de salud es el concepto más general que comprende las nociones de turismo médico y de bienestar.

Para Heung y otros (2010), el turismo de salud es "el proceso por medio del cual una persona viaja para obtener servicios de salud en un país diferente a su país de origen" (De la HozCorrea y otros, 2018: 35). Sin embargo, el turismo de bienestar tiene como objetivo preservar o promover la salud (Gill y Singh, 2011), y en este sentido, y para aclarar las diferencias con el turismo de salud y médico, Koncul expone lo siguiente (2012: 530):

El turismo de bienestar busca crear armonía entre la salud mental, física, espiritual y biológica y está más relacionado con un cambio en el estilo de vida o hacer algo saludable que con la curación de una enfermedad específica. El concepto de bienestar es el producto de la interacción entre una mayor conciencia de la salud, el bienestar y la felicidad y es un proceso activo a través del cual per-

4 Disponible en: https://www.oecd.org/els/health-systems/48723982.pdf [fecha de consulta: 15 de enero de 2020].

5 OECD (2010: 31): "Medical tourism is related to the broader notion of health tourism which, in some countries, has longstanding historical antecedents of spa towns and coastal localities, and other therapeutic landscapes". 
sonas toman conciencia y toman decisiones para lograr una existencia más exitosa. Aboga por una perspectiva positiva y optimista, y un enfoque holístico y equilibrado de la vida y abarca aspectos físicos, espirituales, intelectuales, emocionales, sociales y ocupacionales de la vida.

Con respecto al turismo médico, y en el mismo sentido de la OCDE, Connell (2006) distingue entre la salud y la medicina, y aclara que se trata de turismo médico siempre que haya una intervención médica específica. Por el contrario, y en el mismo sentido de la OMT, autores como Sarwar y otros (2012) utilizan el concepto de turismo de salud para referirse al de turismo médico.

Como podemos observar, los tres conceptos tienen límites muy difusos, suelen incluirse entre sí y no existe una definición unívoca al respecto. Sin embargo, sí que nos sugieren dos elementos clave como son el viajar a otro país con el objetivo de obtener un tratamiento médico (no urgente) y que suelen ser privados. En lo que respecta al presente trabajo, nos basaremos en la idea de Smith y Puczko (2009), compartida por muchos otros autores, según la que el concepto de turismo de salud engloba a los otros dos tipos de turismo, y consideramos, además, que se complementan en mayor o menor grado, en función de las necesidades de cada individuo. Para ello, nos apoyamos igualmente en la tabla que presentan De la Hoz-Correa y otros (2018) basándose en Padilla-Melendez y Del-Águila-Obra (2016):

\section{TABLA 1}

Modalidades del turismo de salud (De la Hoz-Correa y otros, 2018).

Fuente: Basado en Padilla-Meléndez y Del-Aguila-Obra (2016)

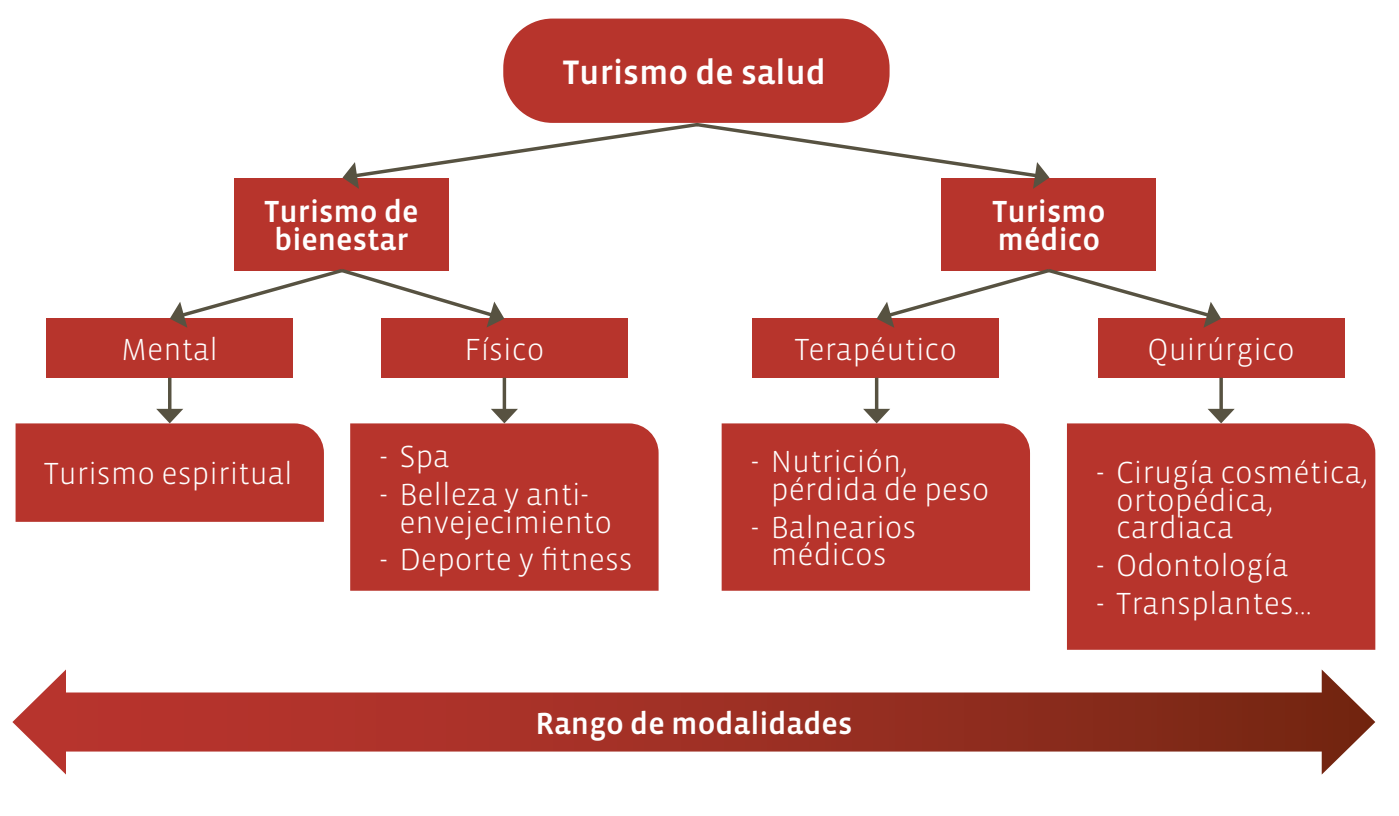

Ambos autores presentan una clasificación del turismo de salud muy completa, a nuestro juicio, en la que el concepto principal engloba al turismo médico y de bienestar, y que incluye todos los aspectos mencionados a lo largo del presente apartado. 


\subsection{Orígenes del turismo de salud}

Según los datos presentados en el presente trabajo, podría parecer que este fenómeno comienza y crece exponencialmente en las últimas décadas. Sin embargo, existen evidencias científicas que lo sitúan en la antigüedad egipcia, mesopotámica, india y china (Kazemi, 2007), cuando las personas peregrinaban a los templos sagrados para bañarse en sus aguas termales o para obtener tratamientos medicinales. Es decir, en la Edad Antigua, ya se iniciaron viajes a las ciudades con aguas termales para mejorar la salud. Este es el caso también de Grecia y Roma, donde destacan igualmente los viajes a los baños termales, tal y como aparece en los relatos sobre viajes históricos al santuario de Asclepios, entre otros (Arias Aragones y otros, 2012). Resulta significativo destacar aquí que ya en la antigua Roma estos viajes a los baños termales con fines medicinales no solo estaban relacionados con la salud, sino que igualmente estaban vinculados al estatus social de la élite que podía realizar dichos viajes. Esta práctica fue creciendo a lo largo del Imperio gracias al comercio con países como Persia, África y Asia, y se incorporaron ciertos aspectos de su medicina a los baños y masajes ayurvédicos (Kazemy, 2007).

El periodo en el que la medicina creció de manera exponencial fue, quizás, la época de expansión del mundo islámico (Pérez, 2010). Médicos como Ibn Sina, el cirujano Abul-Qasim al Zahrawi o Ibn Shaprut, entre otros, transmitieron su saber a lo largo del territorio y bebieron de las fuentes clásicas ${ }^{6}$. Fueron los primeros en crear los primeros hospitales, como el hospital Mansuri en el año 684, a los que acudían personas de todo el territorio y clase social en busca de la sanación (Kazemy, 2007). Según autores como Arias Aragones y otros (2012: 81),

[l]a creación de los hospitales es uno de los más destacados aportes de la medicina islámica. Sin embargo, el aspecto más importante de ésta es su gran sentido social, plasmado en el texto guía llamado Wafa, el cual dice que el hospital deberá mantener a todos los pacientes, hombres o mujeres, hasta que estén completamente curados. Todos los gastos corren a cargo del hospital. No importa que la gente venga de lejos o de cerca, sean residentes o extranjeros, fuertes o débiles, ricos o pobres, empleados o desempleados, ciegos o con deficiencia visual, física o mentalmente enfermos, cultos o analfabetos...

En este sentido, ya se pone de manifiesto en el Wafq la realidad imperante en la época de los viajes para recibir tratamientos de salud.

6 Cabe destacar que la traducción en esta época jugó un papel relevante en la transmisión del conocimiento científico y de la "internacionalización" de las prácticas médicas. Con la expansión del Islam y su ocupación de territorios en los que se cultivaba la ciencia griega, tales como Alejandría, Siria, Persia, etc., los médicos árabes bebieron de la medicina griega y romana y tradujeron sus obras a distintos idiomas. Entre estos médicos, podemos mencionar a Yuhanna ibn Masawaih, que fue el responsable de unas cincuenta traducciones de calidad. Esto llevó a la institución de la casa de la ciencia, Bayt al Hikma, en Bagdad, donde Ibn Ishaq, al frente de un grupo de traductores, tradujo al árabe obras griegas, persas, sánscritas, etc. Disponible en https://historia.nationalgeographic.com.es/a/medicos-islam_8595/6 [fecha de consulta: 20 de marzo de 2020]. 
Con respecto a la zona asiática en la época medieval, destaca Japón por la popularidad de sus aguas termales y la cantidad de viajes en torno a las mismas. Del mismo modo y sin pensar en una época concreta, no podemos olvidar el papel que ha tenido la medicina en la India a lo largo de los siglos. Con el yoga y el Ayur Veda han atraído a personas de todo el mundo en busca de la sanación física y espiritual (Arias Aragones y otros, 2012) y es un referente en lo que se conoce como medicina alternativa?. Igualmente, en China, el Tao y el tratamiento de las enfermedades en la medicina tradicional mediante el uso de la fitoterapia, la acupuntura, los masajes o la dieta hizo que se convirtiera en un centro de referencia en medicina alternativa.

Por otra parte, y según afirman Arias Aragones y otros (2012), durante el periodo renacentista en Europa no solo creció y se desarrolló el arte y la cultura convirtiéndose en un referente mundial, sino que el turismo de salud, y en concreto las zonas con aguas termales, se transformaron en lugares de referencia para viajeros de toda Europa ${ }^{8}$. En el siglo XVI se pusieron de moda las ciudades con balnearios como Aachen, Baden Baden, Bath, St. Mortiz o Ville d’Eaux, a donde viajaba la élite europea.

Esta tendencia continuó a lo largo de los siglos posteriores hasta la actualidad y este tipo de viajes se hizo muy popular (Holden, 2006). Como podemos observar en lo mencionado con anterioridad, el turismo de salud existe desde tiempos remotos. A lo largo de los siglos han existido dos corrientes principales que se han centrado en la búsqueda de la sanación en los baños termales, como ocurrió en la antigua Roma y Grecia o en la Europa de los siglos XVII al XIX, o la búsqueda de una medicina alternativa a la occidental en Asia.

En la actualidad, es un hecho que la globalización ha influido directamente en los servicios de salud que se ofrecen tanto a nivel nacional como internacional (Smith y otros, 2011). Otros aspectos que han contribuido a la movilización de los pacientes entre países en busca de soluciones médicas son, entre otras cuestiones, el precio de los servicios médicos (como, por ejemplo, la cirugía), las listas de espera, la innovación en tecnología y ciertas habilidades médicas populares en determinados países de destino, además del uso de internet, el marketing, etc. (Connell, 2006).

A continuación, revisaremos el contexto español, centrándonos en los facilitadores de turismo de salud que operan a nivel internacional.

\section{España, destino de salud}

La salud es uno de los servicios más demandados por los ciudadanos de todo el mundo. En el caso español, nuestro país se sitúa en el sexto puesto en el ranking europeo y en el octavo a

7 Según Connell (2006) India es el centro mundial del turismo médico gracias a la oferta tan variada de la que dispone, en la que destacan la terapia ayurvédica alternativa, la cirugía estética y los bypass coronarios.

8 En estaépocasurgeel términospa, de la expresión romana salute peraqua o salud a través de las aguas. 
nivel mundial en número de turistas relacionados con la salud. De hecho, según el IDIS (Instituto para Desarrollo e Integración de la Sanidad)9 en 2019 alrededor de 140.000 visitantes optaron por contratar servicios médicos en centros privados en España. Si cuantificamos económicamente estos datos, según el informe del facilitador de turismo de salud español Spaincares $^{10}$, en 2017 este tipo de turismo generó una facturación de 500 millones de euros y se prevé que en 2020 ascienda a un millón de euros y se atienda a unos 200.000 turistas.

Según el informe más reciente publicado por el Ministerio de Industria, Energía y Turismo ${ }^{11}$ de 2013 sobre turismo de salud en España (MIET: 14),

[e]l turismo de salud puede enfocarse como una verdadera oportunidad en España, si se potencia la atención sanitaria privada, mediante la estructuración de un producto que aproveche la demanda creciente identificada para generar una industria turística que diversifique y complemente la actual, y ayude a desestacionalizar la oferta turística más tradicional en España.

Según dicho informe, el turismo de salud es una potencia aún por desarrollar. No obstante, aunque no se haya aprovechado todo su potencial, ya existe lo que la OCDE Ilama "agentes del turismo de salud" y que nosotros denominamos facilitadores de salud. Su función es la de promocionar una serie de servicios sanitarios y turísticos a través de ciertos intermediarios; esto se resume en el esquema mostrado a continuación:

\section{TABLA 2}

Facilitadores de salud (Ministerio de Industria, Energía y Turismo, 2013: 20)

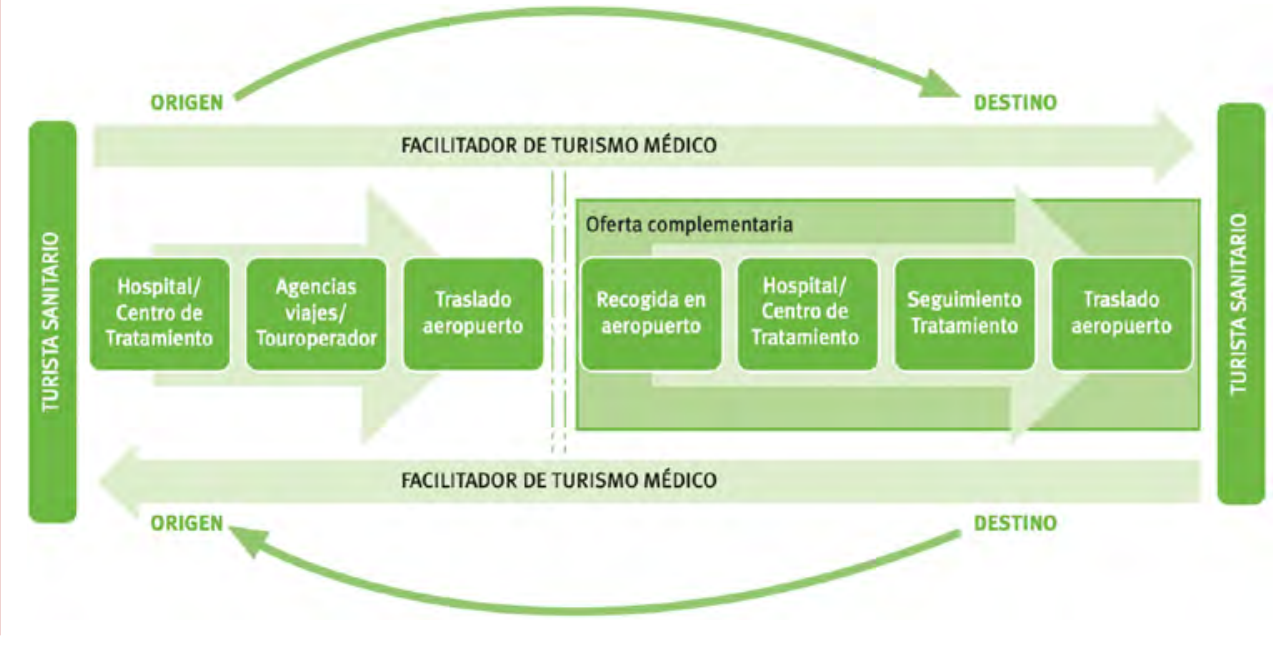

9 Véase https://www.fundacionidis.com/ [fecha de consulta: 20 de febrero de 2020].

10 Véase https://www.spaincares.com/?lang=es [fecha de consulta: 20 de febrero de 2020].

11 Disponible en https://turismo.gob.es/es-ES/Servicios/Documents/turismo_salud_espana.pdf. [fecha de consulta: 20 de febrero de 2020]. 
Como podemos observar, no solo se trata de la asistencia médica que necesiten los pacientes, sino del acompañamiento global en todo el periodo que estén en España.

Los servicios y tratamientos más demandados del turismo de salud en nuestro país, según diversos estudios de la OCDE, Deloitte o McKinsey, publicados en el informe del MIET (2013: 25) son los siguientes:

- Reproducción asistida.

- Cirugía estética y plástica.

- Cardiología.

- Oncología.

- Urología.

- Traumatología.

- Oftalmología.

- Odontología.

- Rehabilitación.

- Nutrición y terapias naturales.

- Anti-aging y estética.

- Bienestar: termalismo, terapias alternativas.

- Cuidados a personas dependientes, rehabilitación y servicios residenciales.

Asimismo, las zonas donde más se concentra la oferta de este tipo de salud son Mallorca, Alicante, la Costa del Sol, Madrid, Barcelona, Badajoz, Navarra y Asturias:

\section{IMAGEN 1}

Zonas de España en las que se concentra la oferta más amplia de turismo de salud. Fuente: Ministerio de Industria, Energía y Turismo (2013: 39)

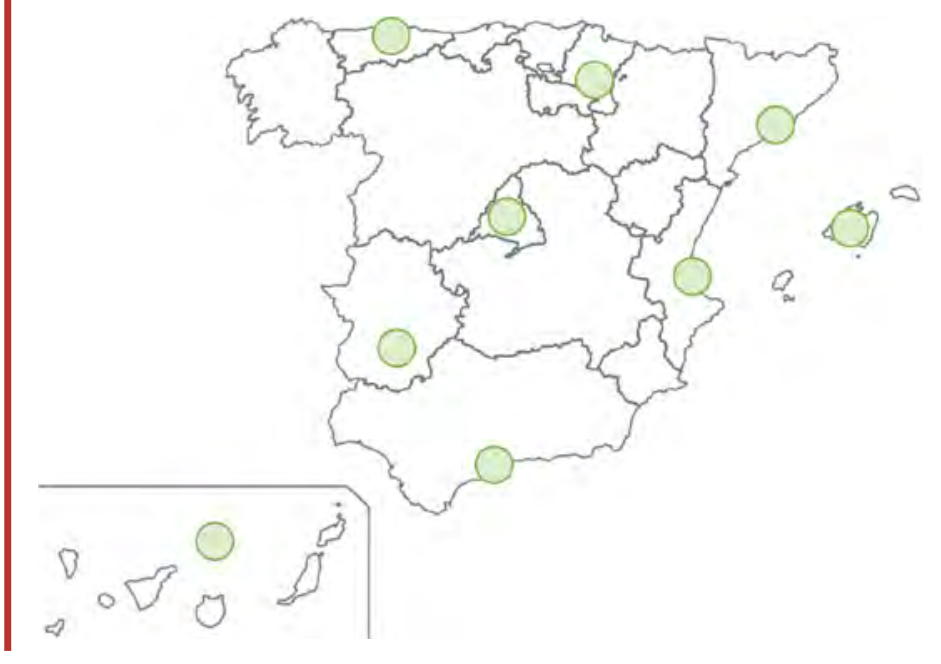


Debemos destacar igualmente la oferta complementaria de la que dispone España, que gira en torno a cinco grandes ejes: el turismo gastronómico, el deporte, el turismo en la naturaleza, el wellness y el turismo cultural. Según el mencionado informe, dichos servicios son tanto compatibles como complementarios. Además, estos servicios se han de completar con los distintos agentes que se encarguen de organizar la experiencia completa:

\section{TABLA 3}

Agentes complementarios al turismo de salud (Ministerio de Industria, Energía y Turismo, 2013: 49)
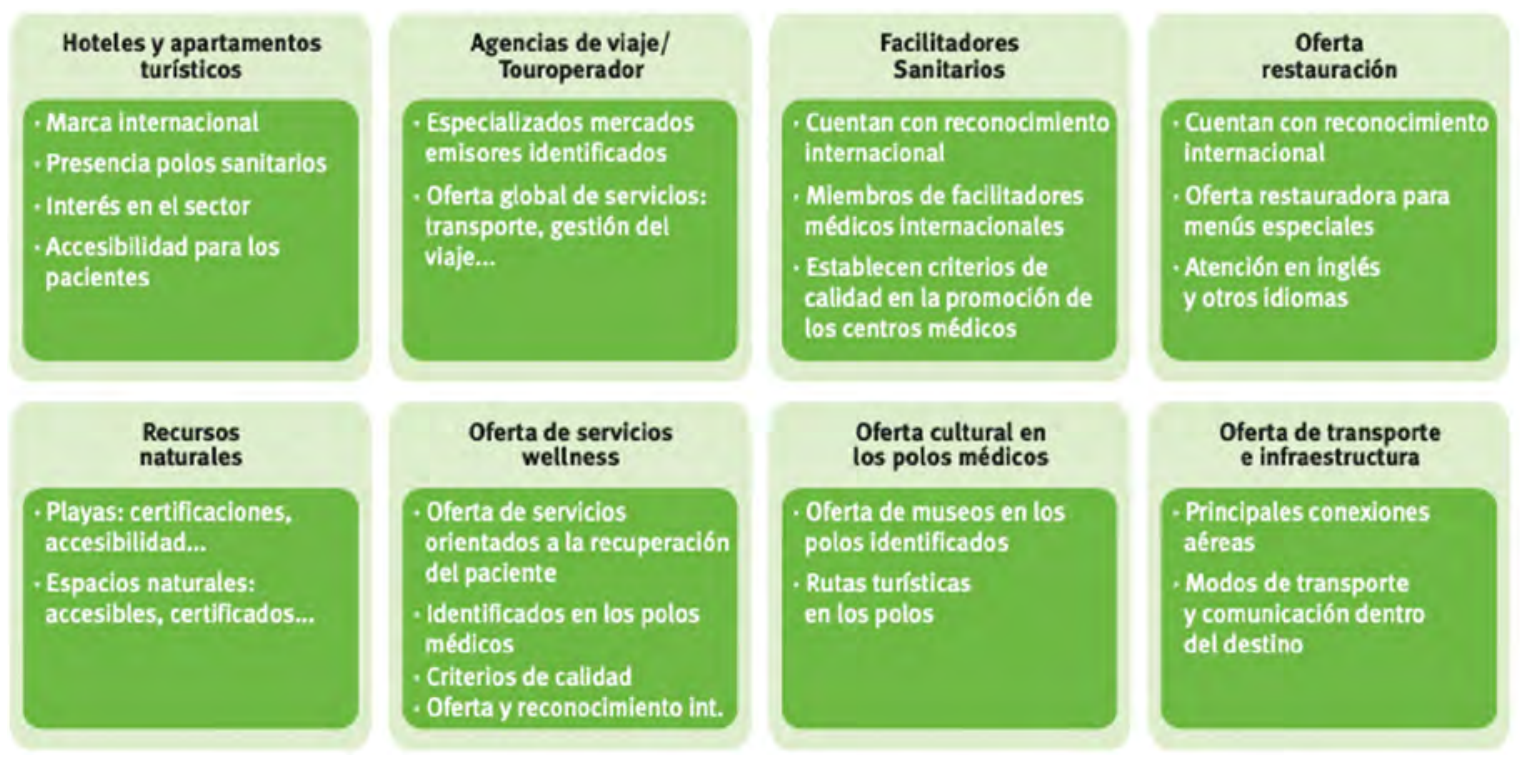

Así, atendiendo a los datos expuestos en el presente apartado, el facilitador de turismo de salud deberá promocionar una oferta sanitaria que incluya los servicios y las demandas sanitarias y complementarias para los pacientes y su entorno. En este sentido, las asociaciones y entidades que representan al sector de la sanidad privado se han organizado y han generado espacios de trabajo conjunto para su promoción.

\section{Facilitadores de salud: contextualización, accesibilidad y análisis}

Tal y como afirman los expertos (MIET, 2013: 57), la principal vía de captación de clientes del turismo de salud es Internet. Asimismo, afirman que "en ese sentido es esencial que las webs corporativas de los centros de salud dispongan de una adecuada accesibilidad (idiomas) y un buen posicionamiento en los buscadores" (ibíd.). En el presente trabajo, nos centraremos en analizar la accesibilidad de los facilitadores de turismo de salud en España. Para ello, realizaremos un análisis dividido en dos partes. En primer lugar, partiremos del facilitador más destacado a nivel internacional: el International Medical Travel 
Journal12 para revisar los agentes y facilitadores de turismo de salud que ofrece España ${ }^{13}$ a través de dicho portal. Una vez estudiadas cada una de las webs de dichos agentes y facilitadores, seleccionaremos las que tengan mayor visibilidad internacional (traducción a distintos idiomas) para profundizar en su traducción y obtener la respuesta a la pregunta que planteábamos al inicio.

El facilitador International Medical Travel Journal (www.imtj.com) es conocido internacionalmente y se conforma como una plataforma en la que agentes, facilitadores, proveedores y organizaciones relacionadas con la salud convergen y ponen su información a disposición del consumidor. Se creó en 2007 como respuesta a la creciente demanda de servicios de turismo médico o de salud y se encuentra redactada únicamente en inglés.

Las búsquedas se pueden filtrar por país, tratamiento y sector. Si accedemos al apartado de agentes y facilitadores de salud en España, apartado que atañe al presente trabajo, obtenemos 32 resultados, que resumimos en la siguiente tabla (actualizado a 18 de mayo de 2020):

\section{TABLA 4}

Elaboración propia basada en el estudio del facilitador Internatioonal Medical Travel Journal

$\begin{array}{ll}\text { NOMBRE } & \text { RESUMEN DEL CONTENIDO } \\ & \text { IDIOMAS A LOS QUE } \\ \text { ESTÁ TRADUCIDA }\end{array}$

Aliad Se trata de una consultoría de gestión $\quad$ No está traducida. empresarial en la que existe un apartado sobre turismo de salud en España. En ella se incluyen dos organizaciones acreditadas en turismo de salud: Instituto Bernabeu de Alicante y la Clínica Juaneda de Palma de Mayorca. Presentan igualmente un dossier de turismo de salud en español.

\begin{tabular}{lll}
\hline $\begin{array}{l}\text { ASISER (Asisa } \\
\text { Servicios Integrales } \\
\text { De Salud, S.A.U), }\end{array}$ & $\begin{array}{l}\text { Nos lleva a la página web de Asisa, } \\
\text { aseguradora privada con sede en } \\
\text { España y que presta servicios a } \\
\text { nacionales e internacionales. }\end{array}$ & No está traducida. \\
\hline $\begin{array}{l}\text { Assistance Health } \\
\text { Company }\end{array}$ & Centro médico de EE. UU. & $\begin{array}{l}\text { Solo disponible } \\
\text { en inglés. }\end{array}$ \\
\hline
\end{tabular}

12 Otros facilitadores de salud destacados son: Ia plataforma Treatment Abroad, Medical Tourism Association, el grupo francés Green4Care y la empresa alemana Med2Heal, entre otros.

13 Otros facilitadores de salud destacados en España son: el Grupo Medical Stay, Medical Care Spain o Intermedical Solutions, entre otros. 


\begin{tabular}{|c|c|c|}
\hline Autran Dental Studio & $\begin{array}{l}\text { Clínica dental que ofrece servicios } \\
\text { internacionales con sede en Barcelona. }\end{array}$ & No está traducida. \\
\hline Canary Medical key & $\begin{array}{l}\text { Agencia de servicios de salud - } \\
\text { facilitadores de turismo médico. }\end{array}$ & $\begin{array}{l}\text { Inglés, alemán, } \\
\text { francés y ruso. }\end{array}$ \\
\hline Celvitae & $\begin{array}{l}\text { Clínica y laboratorio de } \\
\text { investigación en células madre. }\end{array}$ & No está traducida. \\
\hline $\begin{array}{l}\text { Consultorio } \\
\text { Ginecológico Miramón }\end{array}$ & $\begin{array}{l}\text { Centro especializado en } \\
\text { ginecología en Guipúzcoa. }\end{array}$ & No tiene página web. \\
\hline Costa Calida Cares & $\begin{array}{l}\text { Asociación privada de spas, hospitales } \\
\text { y servicios complementarios. }\end{array}$ & $\begin{array}{l}\text { Solo disponible } \\
\text { en inglés. }\end{array}$ \\
\hline Crio Crod & Laboratorio y banco de células madre. & Ya no existe. \\
\hline Doctour & $\begin{array}{l}\text { Centro especializado en } \\
\text { cirugía y hepatología. }\end{array}$ & Ya no existe. \\
\hline FertilisKerr & Centro de reproducción asistida. & Ya no existe. \\
\hline FIDIAS & $\begin{array}{l}\text { Consultoría científica y técnica sobre } \\
\text { normas ISO (no está relacionado } \\
\text { directamente con el turismo de salud). }\end{array}$ & Inglés, francés y ruso. \\
\hline General Surgery & $\begin{array}{l}\text { Empresa de turismo médico } \\
\text { especializada en tratamiento } \\
\text { hospitalario y cirugía cosmética. }\end{array}$ & Inglés. \\
\hline HealthCare Expert & Agencia de viajes médicos en Málaga. & $\begin{array}{l}\text { Inglés, francés y } \\
\text { alemán. Página } \\
\text { vinculada a } \\
\text { andalucia.org. }\end{array}$ \\
\hline Iber Salud & Clínicas dentales en Madrid. & No tiene página web. \\
\hline $\begin{array}{l}\text { IOM Centro Medico } \\
\text { Milenium }\end{array}$ & $\begin{array}{l}\text { Centro médico con distintas especialidades } \\
\text { (cirugía plástica, oftalmología, estética, } \\
\text { etc.) en Tenerife y Las Palmas. }\end{array}$ & No está traducida. \\
\hline Kenko & Facilitador de turismo de salud. & $\begin{array}{l}\text { Solo disponible } \\
\text { en inglés. }\end{array}$ \\
\hline Madrid Medical Travel & Centros dentales en Madrid. & No tiene página web. \\
\hline $\begin{array}{l}\text { Málaga Health } \\
\text { Foundation }\end{array}$ & Facilitador de turismo de salud. & $\begin{array}{l}\text { Página en } \\
\text { construcción. }\end{array}$ \\
\hline $\begin{array}{l}\text { Mallorca Medical } \\
\text { Group }\end{array}$ & Centro especializado en medicina estética. & Inglés. \\
\hline Malo Clinics & $\begin{array}{l}\text { Centro especializado en } \\
\text { odontología en Portugal. }\end{array}$ & $\begin{array}{l}\text { Solo portugués } \\
\text { e inglés. }\end{array}$ \\
\hline Mape Turismo y Salud & Facilitador de turismo. & Ya no existe. \\
\hline
\end{tabular}




\begin{tabular}{lll}
\hline Marbella Surgery & Centro especializado en medicina estética. & $\begin{array}{l}\text { Sitito web en } \\
\text { mantenimiento. }\end{array}$ \\
\hline Más Vida Reproduction & Centro especializado en reproducción. & $\begin{array}{l}\text { Sitito web en } \\
\text { mantenimiento. }\end{array}$ \\
\hline $\begin{array}{l}\text { Medical Advantage } \\
\text { Barcelona }\end{array}$ & $\begin{array}{l}\text { Facilitador de turismo de } \\
\text { salud en Barcelona. }\end{array}$ & $\begin{array}{l}\text { Solo disponible } \\
\text { en inglés. }\end{array}$ \\
\hline Medical Care Spain & Vida saludable y medicina estética. & No está traducida. \\
\hline Mediacal Days & Facilitador de turismo de salud de Valencia. & $\begin{array}{l}\text { No tiene página } \\
\text { web. / Ya no existe. }\end{array}$ \\
\hline Medivip & Centro especializado en medicina estética. & No está traducida. \\
\hline MedTravelCo & Facilitador de turismo de salud. & Inglés. \\
\hline Semesur & Facilitador de turismo de salud. & $\begin{array}{l}\text { Inglés, alemán, francés, } \\
\text { portugués y chino. }\end{array}$ \\
\hline $\begin{array}{l}\text { Tourism \& Health } \\
\text { Costa del Sol }\end{array}$ & Facilitador de turismo de salud & $\begin{array}{l}\text { Página web en } \\
\text { construcción. }\end{array}$ \\
\hline
\end{tabular}

Del análisis y la revisión de la información de las 32 páginas web que presenta el IMTJ como agentes o facilitadores de turismo de salud en España, obtenemos el siguiente resultado. 2 de las páginas anunciadas no son españolas, una es de EE. UU. y otra de Portugal. Una de las páginas está duplicada. De las 29 restantes, 12 no tienen página web o ya no existen. De las 17 restantes, 7 no están traducidas y 5 están publicadas exclusivamente en inglés. De las 5 restantes, una está traducida al inglés, francés, alemán y ruso; otra al inglés, francés y alemán; otra al inglés, francés, alemán, portugués y chino, y dos al inglés. Es decir, de 29 agentes o facilitadores de turismo de salud españoles, únicamente 5 han sido traducidos a otros idiomas y 5 se han publicado directamente en la lengua extranjera (en todos los casos inglés), lo que nos lleva a que solo 10 de los agentes o facilitadores de salud tienen cierta visibilidad internacional.

Este es el resultado que obtenemos del análisis del IMTJ como plataforma mundial de facilitadores de turismo de salud, que, no obstante, muestra que está bastante desactualizada, al menos en lo que respecta a España. Sin embargo, en nuestro país, en 2014 se creó la patronal de turismo sanitario Spaincares para incentivar la llegada de turistas del ámbito de la salud a España. Dicha asociación dio lugar a una plataforma de servicios de salud alojada en www.spaincares. com que cuenta con el apoyo institucional del Gobierno de España y que está patrocinada por Quirón salud, HM hospitales, clínicas y aseguradoras colaboradoras, la Alianza de la Sanidad Privada Española, la Asociación Nacional de Balnearios y la Confederación Española de Hoteles y Alojamientos Turísticos, avales que han hecho que incluyamos dicho facilitador de turismo de salud a nivel nacional para su revisión. Debido a que no podemos hacer un estudio lingüístico exhaustivo ni evaluar la calidad de las traducciones por cuestiones de espacio y conocimiento de idiomas, procederemos a analizar la accesibilidad, y por tanto la visibilidad, de la página web en 
el mercado internacional comparándola con la original y comprobando que se oferta la misma información en todos los idiomas y se respetan las estrategias de mercado dirigidas a la cultura meta. Este mismo tipo de análisis lo realizaremos a las 5 webs de los facilitadores que propone el International Medical Travel Journal para poder dar así respuesta a la pregunta que nos planteamos en el presente trabajo. Para ello, mostraremos los resultados de los análisis a continuación.

\section{A) Spain Cares (www.spaincares.com)}

Con respecto al primer facilitador, lo primero que podemos constatar es que la página web está traducida a 4 idiomas más, entre ellos, inglés, francés, alemán y ruso. Para analizar los resultados, presentaremos el análisis en una tabla con la información que aparece en español y el resto de idiomas:

\section{TABLA 5}

Análisis del facilitador de turismo de salud Spaincares

\begin{tabular}{|c|c|c|c|c|}
\hline ESPAÑOL & INGLÉS & FRANCÉS & ALEMÁN & RUSO \\
\hline $\begin{array}{l}\text { Quiénes } \\
\text { somos }\end{array}$ & $\begin{array}{l}\text { Información } \\
\text { completa. }\end{array}$ & $\begin{array}{l}\text { Información } \\
\text { completa. }\end{array}$ & $\begin{array}{l}\text { Información } \\
\text { completa. }\end{array}$ & $\begin{array}{l}\text { Información } \\
\text { completa. }\end{array}$ \\
\hline Colectivos & $\begin{array}{l}\text { Información } \\
\text { completa. }\end{array}$ & $\begin{array}{l}\text { Falta toda la } \\
\text { información y } \\
\text { el formulario de } \\
\text { inscripción está } \\
\text { en inglés o es- } \\
\text { pañol o francés. }\end{array}$ & $\begin{array}{l}\text { Aparece la informa- } \\
\text { ción, pero está es- } \\
\text { tructurada de forma } \\
\text { distinta. Los formu- } \\
\text { larios de inscripción } \\
\text { están sin traducir } \\
\text { o en otro idioma } \\
\text { distinto al alemán. }\end{array}$ & $\begin{array}{l}\text { Falta toda la } \\
\text { información y } \\
\text { el formulario } \\
\text { de inscripción } \\
\text { está en inglés o } \\
\text { español o ruso. }\end{array}$ \\
\hline $\begin{array}{l}\text { Colabo- } \\
\text { radores }\end{array}$ & $\begin{array}{l}\text { Información } \\
\text { completa. }\end{array}$ & $\begin{array}{l}\text { Información } \\
\text { completa. }\end{array}$ & $\begin{array}{l}\text { Información } \\
\text { completa. }\end{array}$ & $\begin{array}{l}\text { Información } \\
\text { completa. }\end{array}$ \\
\hline Contacto & $\begin{array}{l}\text { Información } \\
\text { completa. }\end{array}$ & $\begin{array}{l}\text { Información } \\
\text { completa. }\end{array}$ & $\begin{array}{l}\text { Información } \\
\text { completa. }\end{array}$ & $\begin{array}{l}\text { Información } \\
\text { completa. }\end{array}$ \\
\hline $\begin{array}{l}\text { Patroci- } \\
\text { nadores }\end{array}$ & $\begin{array}{l}\text { Sin traducir. } \\
\text { Información } \\
\text { en español. }\end{array}$ & $\begin{array}{l}\text { Sin traducir. } \\
\text { Información } \\
\text { en español. }\end{array}$ & $\begin{array}{l}\text { Sin traducir. Infor- } \\
\text { mación en español. }\end{array}$ & $\begin{array}{l}\text { Sin traducir. } \\
\text { Información } \\
\text { en español. }\end{array}$ \\
\hline Acceder & Traducido & Traducido & Traducido & Traducido \\
\hline Registrarse & Traducido & Traducido & Traducido & Traducido \\
\hline Inicio & $\begin{array}{l}\text { Información } \\
\text { completa. }\end{array}$ & $\begin{array}{l}\text { Información } \\
\text { completa. }\end{array}$ & $\begin{array}{l}\text { Información } \\
\text { completa. }\end{array}$ & $\begin{array}{l}\text { Información } \\
\text { completa. }\end{array}$ \\
\hline $\begin{array}{l}\text { ¿Qué ne- } \\
\text { cesitas? }\end{array}$ & $\begin{array}{l}\text { Falta informa- } \\
\text { ción. Mezcla de } \\
\text { idiomas en algu- } \\
\text { nas secciones. }\end{array}$ & $\begin{array}{l}\text { Falta informa- } \\
\text { ción. Mezcla de } \\
\text { idiomas en algu- } \\
\text { nas secciones. }\end{array}$ & $\begin{array}{l}\text { Falta informa- } \\
\text { ción. Mezcla de } \\
\text { idiomas en algu- } \\
\text { nas secciones. }\end{array}$ & $\begin{array}{l}\text { Falta informa- } \\
\text { ción. Mezcla de } \\
\text { idiomas en algu- } \\
\text { nas secciones. }\end{array}$ \\
\hline
\end{tabular}




\begin{tabular}{|c|c|c|c|c|}
\hline $\begin{array}{l}\text { Organiza } \\
\text { tu viaje }\end{array}$ & $\begin{array}{l}\text { Información } \\
\text { completa. }\end{array}$ & $\begin{array}{l}\text { Mezcla de idio- } \\
\text { mas en algunas } \\
\text { secciones. }\end{array}$ & $\begin{array}{l}\text { Mezcla de idio- } \\
\text { mas en algunas } \\
\text { secciones. }\end{array}$ & $\begin{array}{l}\text { Mezcla de idio- } \\
\text { mas en algunas } \\
\text { secciones. }\end{array}$ \\
\hline $\begin{array}{l}\text { ¿Por qué } \\
\text { España? }\end{array}$ & $\begin{array}{l}\text { Información } \\
\text { completa. }\end{array}$ & $\begin{array}{l}\text { Información } \\
\text { completa. }\end{array}$ & $\begin{array}{l}\text { Información } \\
\text { completa. }\end{array}$ & $\begin{array}{l}\text { Información } \\
\text { completa. }\end{array}$ \\
\hline Noticias & Sin traducir. & Sin traducir. & Sin traducir. & Sin traducir. \\
\hline Pie de página & $\begin{array}{l}\text { Información } \\
\text { completa. }\end{array}$ & $\begin{array}{l}\text { Información } \\
\text { completa. }\end{array}$ & $\begin{array}{l}\text { Información } \\
\text { completa. }\end{array}$ & $\begin{array}{l}\text { Información } \\
\text { completa. }\end{array}$ \\
\hline
\end{tabular}

Una vez revisada la página al completo y quedándonos exclusivamente con la información que ha sido traducida o no, y que pueda presentar inconsistencias de contenido, hemos sombreado en naranja las secciones donde o no se ha traducido la información, o hay errores, o se mezclan idiomas entre sí. Sin embargo, aunque pueda parecer que falta mucha información por traducir, hemos de decir que entendemos que la mayor parte de la información de la citada web ha sido traducida con éxito a los 4 idiomas que ofrece. Sin embargo, hay dos secciones que consideramos relevantes, como es la información sobre cómo adherirse a la plataforma y beneficiarse de las mejores ofertas, que la han eliminado, y los formularios de inscripción, que, o no se traducen, o se traducen parcialmente a dos o tres idiomas distintos mezclándolos entre sí. Lo mismo sucede con la información sobre cómo organizar el viaje, ya que mezcla idiomas en las distintas secciones. No obstante, podemos afirmar que el contenido de dicha página es accesible al 90 \% aproximadamente y, por tanto, cumple su función comunicativa y de marketing.

\section{B) Canary Medical Key (https://canarymedicalkey.com/es/inicio/)}

Con respecto al segundo facilitador, tal y como sucedía con el análisis previo, está traducido a 4 idiomas más, entre ellos, inglés, francés, alemán y ruso. Para analizar los resultados, seguiremos el mismo procedimiento que en el caso anterior:

\section{TABLA 6}

Análisis del facilitador de turismo de salud Canary Medical Key

\begin{tabular}{|c|c|c|c|c|}
\hline ESPAÑOL & INGLÉS & ALEMÁN & FRANCÉS & RUSO \\
\hline Inicio & $\begin{array}{l}\text { Información in- } \\
\text { completa. A veces } \\
\text { encontramos más } \\
\text { información en la } \\
\text { versión en español } \\
\text { y otras en inglés. }\end{array}$ & $\begin{array}{l}\text { Traducción } \\
\text { sin revisar. }\end{array}$ & $\begin{array}{l}\text { Información } \\
\text { resumida. No se } \\
\text { valora la calidad } \\
\text { de la traducción. }\end{array}$ & $\begin{array}{l}\text { No se valora la } \\
\text { calidad de la } \\
\text { traducción. }\end{array}$ \\
\hline
\end{tabular}




\begin{tabular}{|c|c|c|c|c|}
\hline Tratamientos & $\begin{array}{l}\text { Incompleta. La } \\
\text { información que se } \\
\text { ofrece en la web en } \\
\text { inglés es un resu- } \\
\text { men del español. }\end{array}$ & $\begin{array}{l}\text { Falta infor- } \\
\text { mación y hay } \\
\text { errores de } \\
\text { traducción. }\end{array}$ & $\begin{array}{l}\text { Información } \\
\text { completa. No se } \\
\text { valora la calidad } \\
\text { de la traducción. }\end{array}$ & $\begin{array}{l}\text { Muy resumido. } \\
\text { No se valora la } \\
\text { calidad de la } \\
\text { traducción. }\end{array}$ \\
\hline Centros & $\begin{array}{l}\text { Incompleta. Falta } \\
\text { información. }\end{array}$ & $\begin{array}{l}\text { Falta infor- } \\
\text { mación y hay } \\
\text { errores de } \\
\text { traducción. }\end{array}$ & $\begin{array}{l}\text { Información } \\
\text { completa. No se } \\
\text { valora la calidad } \\
\text { de la traducción. }\end{array}$ & $\begin{array}{l}\text { Falta infor- } \\
\text { mación. No se } \\
\text { valora la calidad } \\
\text { de la traducción. }\end{array}$ \\
\hline Especialistas & $\begin{array}{l}\text { Información } \\
\text { completa. }\end{array}$ & $\begin{array}{l}\text { Información } \\
\text { diferente y } \\
\text { sin traducir. }\end{array}$ & $\begin{array}{l}\text { Información } \\
\text { completa. No se } \\
\text { valora la calidad } \\
\text { de la traducción. }\end{array}$ & $\begin{array}{l}\text { Información } \\
\text { incompleta. A } \\
\text { veces se tradu- } \\
\text { ce, a veces se } \\
\text { deja en español. }\end{array}$ \\
\hline Servicios & $\begin{array}{l}\text { Información } \\
\text { completa. }\end{array}$ & $\begin{array}{l}\text { Información } \\
\text { incompleta. }\end{array}$ & $\begin{array}{l}\text { Información } \\
\text { completa. No se } \\
\text { valora la calidad } \\
\text { de la traducción. }\end{array}$ & $\begin{array}{l}\text { No se valora la } \\
\text { calidad de la } \\
\text { traducción. }\end{array}$ \\
\hline Empresas & No existe. & No existe. & No existe. & No existe. \\
\hline Blog & $\begin{array}{l}\text { No está actualiza- } \\
\text { do. Faltan artículos } \\
\text { por traducir. }\end{array}$ & $\begin{array}{l}\text { No está ac- } \\
\text { tualizado. }\end{array}$ & $\begin{array}{l}\text { No está ac- } \\
\text { tualizado. }\end{array}$ & $\begin{array}{l}\text { No está actua- } \\
\text { lizado. No se } \\
\text { valora la calidad } \\
\text { de la traducción. }\end{array}$ \\
\hline Contacto & $\begin{array}{l}\text { Información } \\
\text { completa. }\end{array}$ & $\begin{array}{l}\text { Traducido, pero } \\
\text { con errores } \\
\text { gramaticales. }\end{array}$ & $\begin{array}{l}\text { Traducido. No se } \\
\text { valora la calidad } \\
\text { de la traducción. }\end{array}$ & $\begin{array}{l}\text { No se valora la } \\
\text { calidad de la } \\
\text { traducción. }\end{array}$ \\
\hline
\end{tabular}

En este y los siguientes casos, hemos procedido de igual manera que en el anterior. En este sentido, podemos afirmar que únicamente existe información completa de casi todo el contenido en inglés. En el caso del francés, reproduce casi toda la información de la web en español, pero no podemos valorar la calidad de su traducción. Sin embargo, en los casos del alemán y, sobre todo, el ruso, falta mucha información y hemos constatado que existen numerosos errores de traducción. Entendemos que la mayor parte de la información de la citada web ha sido traducida con éxito a uno o dos de los cuatro idiomas que ofrece. En este sentido, consideramos que el contenido de dicha página es accesible en un porcentaje muy bajo y, por tanto, no cumple con su función comunicativa y de marketing, salvo en inglés.

\section{C) HealthCare Expert (https://www.andalucia.org/es/malaga-agencias-de-viajes-healthca- re-expert)}

El tercer facilitador ha sido traducido al inglés, francés y alemán y está vinculado a la página de turismo andaluz www.andalucia.org. Se trata de una página enlazada a la web principal en 
la que se pone a disposición del turista toda la información existente en la página oficial de turismo de Andalucía. Observamos que la breve información que aparece sobre el facilitador solo ha sido traducida al inglés (aunque son únicamente dos párrafos). En francés y alemán solo se han traducido los enlaces y los titulares que llevan a otras páginas. No valoraremos esta página puesto que forma parte de una web global oficial cuya función no es la de un facilitador de turismo de salud.

\section{D) Mallorca Medical Group (www.mallorcamedicalgroup.com)}

El cuarto facilitador ha sido traducido exclusivamente al inglés y, tras revisar los distintos apartados, podemos afirmar que prácticamente casi todo el contenido está bien traducido. Únicamente existen algunos apartados en los que han resumido la información o la han reunido bajo un único epígrafe por estar relacionada. En este caso, podemos asumir que dicha página es accesible en un porcentaje muy elevado (95\%) y que cumple con su función comunicativa y de marketing.

\section{E) MedTravelCo}

El quinto facilitador únicamente está traducido al inglés. En este caso, llama especialmente la atención que la página web traducida tiene una estructura diferente a la original y ha reducido significativamente la información que publica en el otro idioma.

\section{TABLA 7}

Análisis del facilitador de turismo de salud MedTravelCo

\begin{tabular}{ll} 
ESPAÑOL & INGLÉS \\
\hline Inicio & Home \\
\hline Selección de sexo & $\begin{array}{l}\text { Medical Specialities: Fertility, } \\
\text { dental, cosmetic surgery, others. }\end{array}$ \\
\hline Reducción de estómago & Medical Centers \\
\hline $\begin{array}{l}\text { Tratamientos: Fertilidad, gestación subro- } \\
\text { gada, medicina estética, dental, otros. }\end{array}$ & FAQS \\
\hline $\begin{array}{l}\text { Paquetes: Fertilidad, gestación subrogada, } \\
\text { medicina estética, dental, especialidades }\end{array}$ & \\
\hline Nosotros & About us \\
\hline Blog & Blog \\
\hline
\end{tabular}

Nos gustaría destacar que en el caso del español, la información que aparece bajo las categorías de tratamientos y paquetes es muy similar, redirigiendo la página de una categoría a otra para más información. En el caso del inglés, incluyen la información sobre los tratamientos, 
paquetes, selección de sexo y reducción de estómago en una única categoría denominada Medical Specialities y de forma resumida. Del mismo modo, observamos que en inglés existe una categoría FAQS que no aparece en la web original. Asimismo, hemos constatado que hay errores de traducción. No obstante, podríamos decir que cumple con el objetivo de hacer visibles y accesibles los servicios que ofertan. En este caso, consideramos que no se trata de una traducción, sino de una adaptación y reorganización del contenido.

\section{F) Semesur}

El sexto y último facilitador que ha traducido su página web lo ha hecho al inglés, alemán, francés, portugués y chino. Sin embargo, no se trata de un facilitador de turismo de salud en sí, sino que se trata de un proveedor de servicios médicos exclusivamente, por lo que no ofrece otro tipo de servicios.

\section{TABLA 8}

Análisis del proveedor Semesur

\begin{tabular}{|c|c|c|c|c|c|}
\hline ESPAÑOL & INGLÉS & ALEMÁN & FRANCÉS & PORTUGUÉS & CHINO \\
\hline Servicios & $\begin{array}{l}\text { Información } \\
\text { completa. }\end{array}$ & $\begin{array}{l}\text { Traducción } \\
\text { sin revisar. }\end{array}$ & $\begin{array}{l}\text { Información } \\
\text { traducida. No } \\
\text { se valora la } \\
\text { calidad de la } \\
\text { traducción. }\end{array}$ & $\begin{array}{l}\text { Información } \\
\text { traducida. No } \\
\text { se valora la } \\
\text { calidad de la } \\
\text { traducción. }\end{array}$ & $\begin{array}{l}\text { Información } \\
\text { traducida. No } \\
\text { se valora la } \\
\text { calidad de la } \\
\text { traducción. }\end{array}$ \\
\hline $\begin{array}{l}\text { Ámbito de } \\
\text { actuación }\end{array}$ & $\begin{array}{l}\text { Información } \\
\text { completa. }\end{array}$ & $\begin{array}{l}\text { Traducción } \\
\text { sin revisar. }\end{array}$ & $\begin{array}{l}\text { Información } \\
\text { traducida. No } \\
\text { se valora la } \\
\text { calidad de la } \\
\text { traducción. }\end{array}$ & $\begin{array}{l}\text { Información } \\
\text { traducida. No } \\
\text { se valora la } \\
\text { calidad de la } \\
\text { traducción. }\end{array}$ & $\begin{array}{l}\text { Información } \\
\text { traducida. No } \\
\text { se valora la } \\
\text { calidad de la } \\
\text { traducción. }\end{array}$ \\
\hline La empresa & $\begin{array}{l}\text { Información } \\
\text { completa. }\end{array}$ & $\begin{array}{l}\text { Traducción } \\
\text { sin revisar. }\end{array}$ & $\begin{array}{l}\text { Información } \\
\text { traducida. No } \\
\text { se valora la } \\
\text { calidad de la } \\
\text { traducción. }\end{array}$ & $\begin{array}{l}\text { Información } \\
\text { traducida. No } \\
\text { se valora la } \\
\text { calidad de la } \\
\text { traducción. }\end{array}$ & $\begin{array}{l}\text { Información } \\
\text { traducida. No } \\
\text { se valora la } \\
\text { calidad de la } \\
\text { traducción. }\end{array}$ \\
\hline Contacto & $\begin{array}{l}\text { Información } \\
\text { completa. }\end{array}$ & $\begin{array}{l}\text { Traducción } \\
\text { sin revisar. }\end{array}$ & $\begin{array}{l}\text { Información } \\
\text { traducida. No } \\
\text { se valora la } \\
\text { calidad de la } \\
\text { traducción. }\end{array}$ & $\begin{array}{l}\text { Información } \\
\text { traducida. No } \\
\text { se valora la } \\
\text { calidad de la } \\
\text { traducción. }\end{array}$ & $\begin{array}{l}\text { Información } \\
\text { traducida. No } \\
\text { se valora la } \\
\text { calidad de la } \\
\text { traducción. }\end{array}$ \\
\hline Blog & $\begin{array}{l}\text { No está } \\
\text { actualizada. }\end{array}$ & $\begin{array}{l}\text { No está } \\
\text { actualizada. }\end{array}$ & $\begin{array}{l}\text { No está } \\
\text { actualizada. }\end{array}$ & $\begin{array}{l}\text { No está } \\
\text { actualizada. }\end{array}$ & $\begin{array}{l}\text { No está } \\
\text { actualizada. }\end{array}$ \\
\hline
\end{tabular}

En el caso de este proveedor, podemos confirmar que transmite su información en inglés de forma completa y, por tanto, crea una web accesible y visible a posibles clientes extranjeros. 
Sin embargo, tras analizar el contenido de la web en alemán, nos atrevemos a aventurar que se trata de una traducción automática que no ha sido revisada. Este tipo de traducciones pueden producir un efecto negativo en el cumplimiento de su objetivo de visibilidad y accesibilidad. La autora no tiene conocimientos de los otros dos idiomas, por lo que no puede valorar la calidad de las traducciones.

Por último y a modo de resumen tras haber revisado las páginas web de los seis facilitadores de turismo de salud (uno de ellos es un proveedor y no un facilitador), observamos que sí se cumple el objetivo de accesibilidad y visibilidad internacional al menos en el idioma inglés. No obstante, si tenemos en cuenta las cifras globales resultantes del presente estudio, consideramos que los facilitadores de turismo de salud españoles tienen poca visibilidad internacional y no son accesibles para los potenciales clientes extranjeros, ya que solo 6 de las 30 páginas estudiadas han traducido sus contenidos a uno o más idiomas.

\section{Conclusiones}

El análisis realizado en los epígrafes previos nos lleva a las siguientes conclusiones:

- Existe una gran cantidad de agentes y facilitadores de turismo de salud en España que pretenden promover los servicios de salud a nivel internacional.

- La traducción de las páginas web de los facilitadores de turismo de salud es necesaria a todos los efectos y niveles, pero principalmente para que los destinos de salud tengan visibilidad internacional y sean accesibles para los clientes extranjeros.

- No obstante, la necesidad de dicha traducción no se ve plasmada en la realidad de las webs analizadas a nivel internacional. Si bien es cierto que alguna de las webs consigue comunicar la información requerida por los clientes, la gran mayoría de ellas no están traducidas o solo lo hacen a un idioma y, muchas veces, con errores.

- Los conceptos de turismo de salud, turismo médico y turismo de bienestar coexisten en la actualidad y aún es confusa la línea que los delimita.

\section{Bibliografía citada}

Arias Aragones, Francisco José, Alexander Mauricio Caraballo Payares y Rodolfo Enrique Matos NAvAs, 2012: "El turismo de salud: conceptualización, historia, Desarrollo y estado actual del mercado global”, Clío América 11, 72-98.

ConnelL, John, 2006: "Medical tourism: Sea, sun, sand and... surgery", Tourism Management 27, 1093-1100. 
De la Hoz-Correa, Andrea, Francisco Muñoz-Leiva y Marta Bakucz, 2018: "Past themes and future trends in medical tourism research: A co-word analysis", Tourism Management 65, 200-211.

GIL, Harsimran, y Neha SINGH, 2011: "Exploring the factors that Affect the Choice of Destination for Medical Tourism", Journal of Service Science and Management 4, 315-324.

Heung, Vincent C.S., Deniz Kucukusta y Haiyan Song, 2010: "A Conceptual Model Of Medical Tourism: Implications for Future Research", Journal of Travel Tourism Marketing 27, 236-251.

Holden, Andrew, 2006: Tourism Studies and the Social Sciences, London: Routledge.

KazemI, Zahra, 2007: Study of the effective factors for attracting medical tourism in Iran. Tesis de maestría, Lulea University of Technology, Irán.

Koncul, Niko, 2012: "Wellness: A New Mode of Tourism", Economic Research - Ekonomska Istraživanja 25 (2), 525-534.

Pérez Fontán, María José, 2010: "Historia de la farmacia" [http://historiadelafarmacia.perezfontan.com/cap_5.html, fecha de consulta: marzo de 2020].

Sarwar, Abdullah, Noorhazilah A. Manaf y Azura Omar, 2012: "Medical tourist's perception in selecting their destination: A global perspective”, Iranian Journal of Public Health 41, 1-7.

Smith, Melaine, y László Puczko, 2009: “History, definitions, and scope” en Melaine Smitr y László Puczko (eds.): Health and wellness tourism, New York: Butterworth-Heinemann, 1-130.

Smith, Richard, Melisa Martínez Álvarez y Rupa Chanda, 2011: "Medical tourism: A review of literature and analysis of a role for bi-lateral trade”, Health Policy 103, 276-282.

\subsection{Referencias web}

Informe de la Organización Mundial del Turismo: https://webunwto.s3.eu-west-1.amazonaws. com/s3fs-public/2019-10/3_high_level_forum_on_medical_health_tourism_manuel_butler_ unwto_o.pdf.

Informe del Gobierno de España “Turismo de salud en España”: https://turismo.gob.es/es-ES/ Servicios/Documents/turismo_salud_espana.pdf.

Instituto para el Desarrollo y la Integración de la Sanidad: www.fundacionidis.com.

International Medical Travel Journal: https://www.imtj.com/medical-tourism-agents-andfacilitators/?country=187. 
National Geographic: https://historia.nationalgeographic.com.es/.

OCDE. Informe "Medical Tourism: Treatments, Markets and Health System Implications: A scoping review": https://www.oecd.org/els/health-systems/48723982.pdf.

Organización Mundial del Turismo: www.unwto.org.

Spaincares: www.spaincares.com. 